\title{
INFANT MORTALITY
}

\section{AND PARLIAMENTARY LEGISLATION.}

\author{
By Lieut.-Col. ROBERT CALDWELL, F.R.C.S., \\ D.P.F., R.A.M.C.,
}

Specialist Sanitary Offuer, Western Area, Southern Command.

(MEMBER.)

\begin{abstract}
$\mathrm{A}^{\mathrm{S}}$, in spite of all that has been done, said, and written, the problem A of infant mortality remains one of ever pressing importance, I thought that an effort to forecast the probable effect of certain Parliamentary legislation on the evil in question might be of interest, and afford ground for useful discussion.

I need scarcely say that I am not concerned with the policy of the Government, except in so far as the present question is involved, and I hope to confine my remarks to such issues as bear directly on this branch of sanitary science. With all deference to others, I would venture the opinion that there is a natural tendency among members of the medical profession to limit their attention to the more immediate and apparent causes of infant mortality, such, for instance, as improper feeding and maternal neglect, and to lose sight of the fact that the apparent cause is commonly an offshoot of that growth of sanitary evil of which the roots lie buried, and therefore hidden, deep down in ou national existence; but I think that the doctor might, without in the least stepping beyond his legitimate functions, try to ascertain something of the part played by economic conditions in bringing about results with which we are all, to a greater or less extent, familiar.

Among the causes which lie nearest to the roots of the mischief, and which are, therefore, among the most comprehensive, food and the dwelling are pre-eminently likely to conmand attention, and it is towards the alleviation of these causes that the Parliamentary legislation, to which I propose to invite your attention, is largely directed. By way of bringing the discussion within reasonable limits, I propose to limit the term food to
\end{abstract}


milk only, and to omit any discussion regarding those proprietary articles which flood the market, and the alleged results of which are pictorially displayed throughout the country.

It is a matter of common knowledge that milk farms in general are far removed from that standard of cleanliness which public health demands. Doubtless some defects are easily removable; for instance, it should be criminal to employ as milkers persons who act as though cleanliness were an absurd and rexatious superfuity, and who consider it necessary to spit in their hands as a preliminary to milking. Other defects present greater difficulty; these are generally of a structural nature and camnot be remedied without expense, and herein lies the crux of the question. A formidable barrier to improvement has been found in the fact that farmers being in great measure yearly tenants, and being in consequence practically depenclent on the goodwill of the landlord, and having in the past no regular claim to compensation for improvements, the risk of pecuniary loss without corresponding profit would not be readily incurred.

The pecuniary disadvantage at which the yearly tenant is placed seems too plain to need detailed discussion, yet, strange to say, it has not attracted the attention from sanitarians which its importance demands, and this absence of attention is a most regrettable fact, it being quite fair to assume that insecurity of tenure must induce a desire, possibly blameworthy, but none the less natural, to secure, while the opportunity lasts, as large a profit as possible, by producing milk under the clieapest conditions obtainable, and regardless of the possible consequences to the health of consumers.

Much has been written and much has been said about the conditions of the ileal dairy farm, and yet the stubborn fact remains that the eloquence poured forth at hundreds of meetings of learned societies has never yet fired the tenant farmer with an ambition to risk the pecuniary ruin of himself and his family in the interests of public health, and incidentally in those of his landlord, to whom, of course, improvements would ultimately revert.

Let us now try and form somc idea of the effect that recent enactments may reasonably be expected to exercise on the difficulties I have named.

The enactments to which I refer are, first, Lord Carrington's Agricultural Holdings Act of 1906, and, secondly, the Small Holdings and Allotments Act, which was recently passed into law. It is impossible to enter into details, but, briefly stated, the object of the first of these 
measures is to insure to the tenant compensation for repairs to farm buildings, and for losses incurred through disturbance without just and sufficient cause; and the second effects security of tenure as long as rent is paid and certain reasonable conditions complied with. The effect of those measures cannot be foretold, but in the meantime it clearly comes within our province to watch for results, as it needs no great effort of reasoning to see that granted compensation for improvements, and security of tenure, local authorities can enforce sanitary regulations which, up to the present, have been largely a dead letter, and we can therefore entertain a reasonable hope that Dairy and Milkshops Orders may ultimately be worth considerably more than the paper on which they were drafterl. I cannot refrain from observing that if the owner of the land was legally compelled to bear a clue share of responsibility, the weight of which rests on the tenant, the reformer's dream in the slape of model dairy farms, with resulting benefit in the shape of a diminution in infant mortality, might have been realised long ago.

I am now going to make what may be considered a very heterodox assertion, and one, moreover, which appears to be a direct contradiction of a good deal that I have already said. To put the matter in as few words as possible, I very much question whether, in spite of its far reaching nature, the influence assigned to a pure source for milk has not been greatly exaggerated as regards high rates of infant mortality. (One farm may, and commonly does, supply several shops, or, in the case of large concerns, many farms may supply one central depot. Each shop or depot supplies many customers, so that the persons who obtain milk from the same source may occupy almost every rung of the social ladder. If the source approximately affects all alike, how are we to account for certain remarkable differences in the incidence of infant mortality. For instance, the Parliamentary Secretary to the Local Govermment Board recently stated in public that in 1904 the infant, mortality in St. Mary's, Birmingham, was 331 per 1,000 births, while at Bournville, quite close, it was 6j per 1,000 births. Prof. Glaister of Glasgow has pointed out that in 1901 the average infant mortality for Lancashire, Northumberland and Durham, all colliery and manufacturing districts, was 197 per 1,000 males born, and 163 for females, while Rutland, Wilts and Dorset, all agricultural counties, the average mortality for the same year was 102 per 1,000 for males and 88 for females; he also stated that in Scotland in 1900 in the principal town districts the rate for both sexes was 146.9 per 1,000 , in mainland rural districts it was 94.5 per 1,000 , and in insular rural districts it was 75 per 1,000 . The report for 1906 of the Medical Officer of the 
London County Council reveals an infant death-rate of 94 per 1,000 in Hampstead and 167 per 1,000 in Stepney.

Major R. .J. Blackham, R.A.M.C., in a paper which he recently read before the Institute, ${ }^{*}$ showed that for the decennium 1897 to 1906 the average infant mortality among the married families of H.M. Troops at Devonport was 43.09 per 1,000 births as contrasted with $134 \cdot 6$ per 1,000 in the civil population of the same town; and there is every reason to believe that the milk was largely obtained by both classes from identical sources. Dr. Routley, M.O.H., Aldershot, las set forth some highly interesting figures pointing in the same direction as the above; these figures are as follows: during the quinquemium, 1902-1906, there were 12 deaths from diarrhœal diseases among infants in the town of Aldershot, and 17 from the same cause in the camp. The births in the two districts during this period were in the proportion of 4 to 3 , viz. : 2,800 in the town, and 2,092 in the camp. Dr. Routley also stated that the original source of milk supply was common to both districts; "the milk vendors in the town supplying both districts in their entirety."

I will not weary you further by piling up figures, let it suffice to say that differences in recorded rates of infant mortality are sufficiently striking to excite our interest regarding influences, besides those of food, which are certainly at work. I do not wish to be misunderstood; I have no intention to minimise the importance of a pure milk supply, but I am anxious to assign its approximate value to each factor in the problem which we are now trying to solve.

Doubtless the causes which bring out the difference to which reference has just been made are sufficiently numerous, and so far interdependent as to render it impossible to completely disentangle one from the other, but among all these causes, whatever they may be, a position of supreme importance is occupied by the dwelling, including, of course, all the subsidiary factors comprised therein, such as drink, vice, filth and the greater part of that catalogue of abominations which seem to be naturally associated with the submerged population of our great cities.

How will such conditions be affected by Parliamentary legislation? I think that possibly I may save time and illustrate my meaning by an example. In a large manufacturing town, where I was recently stationed, which possesses the unenviable notoriety of an appalling rate of infant mortality, and where the homes of the artizan class, taken as a whole, are an excellent representation of the most sickening forms of

* “Infant Mortality," Vol. XXYIII., p. 269. 
bestial squalor which it is possible for the human mind to conceive, the ground rents are drawn by two of the wealthiest landowners in the United Kingdom. As leases have fallen in, it has been found that the land has progressively increased in value, this value being naturally due to the enterprise of capitalists and to the skill and industry of labourers, and it represents at present a colossal fortune; yet every farthing of this increase passes into the pockets of private individuals and not one farthing is retained by those who made it. Putting aside the fantastic doctrines which emanate from the distorted intellects of Socialist agitators, we may reasonably ask ourselves the question whether it is consistent with the interests of national well being that some part of the wealth to which I have referred should not be retained for the physical betterment of those to whose exertions it is due, and it is with the object of effecting such retention (judging by the public utterances of responsible persons) that the Land Valuation Bills for England and Scotland have been framed. Omitting details, the general principle of the Bills is to ascertain the true value of the land and to make such valuation a basis for future taxation; the results being applied to housing and other reforms, as to the necessity for which all parties are agreed. To effect these reforms money is. necessary, and as it seems unlikely that much more can be extracted in the way of rates from the poor, and from men of moderate incomes, it is proposed to place the burden on the shoulders of the owner of the land as well as on those of the occupier. As we are fortunately not assembled for political purposes, we need not in the least concern ourselves as to whether His Majesty's Ministers are or are not deserving of those flowers of speech so liberally bestrewn on them, but one fact remains unassailable, that the measures in question afford a reasonably hopeful prospect of dealing satisfactorily with those social conditions of which infant mortality forms an integral part.

It would be a matter of cleep regret to me if I were to utter one disrespectful word concerning the work of ministers of religion, health visitors, and genuine philanthropists, but I cannot but feel that efforts in the direction of advice are in a great measure useless in the case of the inhabitants of such slums as are found in the north of England, and in fact in our large centres of population generally. Lady visitors unquestionably do splendid work, but it appears likely that it is mainly limited to those who are sufficiently hopeful to appreciate advice, and sufficiently well provided with worldly goods to be able to act on it. What is the use of advice to a family occupying a room which serves as sitting room, sleeping room, kitchen, larder, nursery, and maternity ward, with possibly 
a filthy privy hidden in the back yard; and what is the use of preaching decency and self respect, both factors in the problem, when the sexes are huddled together with a promiscuosity which might shock the instinctive modesty of a primeval savage; and what is the use of pointing out the evils of the public-house when, as I heard recently stated, the publichouse is more sanitary than the home? Advice under such circumstances is not only useless, it is an insult. We all, probably, know the story in "Oliver Twist" of the starving pauper who was relieved with a half-pint of oatmeal and a pound of potatoes. "Great heart," said the ungrateful zuffian, "what's the use of this to me, you might as well give me a pair of -green spectacles."

Whether you agree with me or not as to the probable effect of land -valuation, and subsequent taxation of ground rents, on infant mortality, I think you will find that the measure in question is worthy of your .careful attention, and to philanthropists in particular it offers exceptional interest. To two points in particular $I$ invite your attention, one is that infant mortality and overcrowding go hand in hand, and the other is that high ground rents are a direct incentive to the owner of slum property to cram the highest possible number of what I would call paying units into the smallest possible space. It is likewise most important to .observe that as all buildings revert to the ground landlord on the conclusion of the lease, a direct premium exists on the worst forms of jerry building.

I fear that in venturing to discuss a subject that has unfortunately, but, I presume, unavoidably, been thrown into the cock-pit of party politics, I have trodden on delicate or even dangerous ground; but on the other hand I feel conficlent that men whose calling is essentially one of facts, not fancies, are eminently qualified to judge dispassionately of measures which, in their influence on the physical well being of the people, are intimately associated with the honour and integrity of our Empire. 